\title{
The fall of the wild
}

\author{
David P. Mallon and Mark R. Stanley Price
}

One long-term vision for species could be that they persist in viable numbers in representative parts of their indigenous ranges in dynamic and resilient ecosystems over spatial and temporal scales that allow natural selection to take place. Most people would call such populations wild. But with the challenges that biodiversity faces from habitat loss and fragmentation, overuse, pollution and disease, and with threats acting synergistically, how many populations can we really call 'wild'? When does human intervention in the form of habitat manipulation or population support or control render a population no longer wild?

Although wild may be instinctively interpreted as the opposite of tame or managed these states represent the ends of a continuum, and drawing a line between them is not straightforward. The need to define what is wild and non-wild is not just a theoretical issue but one that has practical implications for, inter alia, international agreements (Convention on Biological Diversity, CITES, Convention on Migratory Species), national legislation, lists of protected species and the IUCN Red List, all of which relate to wild species. None of these, however, provide a definition; for example, the current IUCN Red List guidelines state that the process should be applied to wild populations but without defining what constitutes 'wild' (IUCN Standards and Petitions Subcommittee, 2013).

Redford et al. (2011) defined the spectrum of management support for securing threatened vertebrate populations. They proposed five steps to cover the full range of level and type of human intervention in management (self-sustaining, conservation dependent, lightly managed, intensively managed and captive breeding) but did not explicitly distinguish within this typology between wild and non-wild.

Interventions take many forms: habitat creation or manipulation, provision of supplementary food and salt licks, creation of artificial water points, provision of shelter (nest boxes for birds, bat boxes and roosts), predator control, population reinforcement, reintroduction, veterinary measures, and fencing to keep species in or out of an area.

Given the extent of human intervention in biodiversity conservation, excluding any management effort from

DAvid P. MALlon 3 Acre Street, Glossop, Derbyshire, SK13 8JS, UK. E-mail dmallon7@gmail.com

Mark R. Stanley Price Wildlife Conservation Research Unit, Department of Zoology, University of Oxford, The Recanati-Kaplan Centre, Tubney, UK consideration of what is wild is impractical as it would render many populations and species non-wild. The dividing line would appear most logically placed between lightly and intensively managed (sensu Redford et al., 2011) and the type of, and degree of dependence on, the management intervention assessed on a case-by case basis-resulting perhaps in a somewhat fuzzy line rather than a precise definition with universal applicability.

Vultures in south and south-east Asia have been provided with clean carcases free of toxins, such as diclofenac, at vulture restaurants; are vultures in those areas mainly or wholly dependent on this food thereby non-wild? Are bird populations heavily dependent on winter food at garden bird tables wild? Does living in gardens and orchards count as being in the wild? Wherever the theoretical line between wild and non-wild is drawn, as the numbers and distributions of many species shrink and become more fragmented there is an undeniable trend for many of those remaining to receive increasing levels of management intervention and thus become less wild.

Fragmentation as a result of anthropogenic activities is exacerbated by confinement within fenced areas to protect from overharvesting and encroachment, further hindering movement of individuals-and genetic exchange-between subpopulations. Most cheetahs and wild dogs in South Africa will be dependent in the long term on movement of individuals between small subpopulations in fenced areas.

Management becomes more intensive (e.g. culling to control numbers) when the ecosystem remnants become so small they are no longer self-regulating: increasing rarity means more species need specific conservation interventions. Measures are intensified when rare species acquire great commercial value: thus rhinos increasingly need military-quality protection measures, with fenced sanctuaries being developed both outside and inside African protected areas. Even if rhinos carry on their normal habits inside the fenced area, do these measures mean they are no longer wild?

There is a parallel with changes in the concept of naturalness. Landscape scale intervention began when early humans used fire and tools to modify the habitats in which they lived, and developed further with the domestication of wild animals and cultivation of crops. As Pearce (2013) has shown, a fifth of the land across the world had been transformed by humans as early as 5,000 years ago-a proportion that past studies of historical land use had assumed was only reached in the past 100 years or so. Much primary tropical rain forest is now seen to be secondary 
growth, and the supposedly pristine Amazon basin shows signs of historical civilisations that collapsed and whose infrastructures have been reclaimed by forest, and are barely detectable.

Visitors become accustomed to parks where wildlife viewing is good, encouraging managers to favour popular species and manage habitat to promote them. Thus managed habitats and animal communities become the norm and expectations of wildness changes. A shifting baseline between generations is real: what a parental generation grew up knowing as common is often now rare and this will influence the next generation. Will this situation spread globally as the world's population aspires to consumerist lifestyles in which exposure to nature is second hand, through increasingly brilliant media productions (Pyle, 2003)?

A prevalent myth in the UK is the perception of intensively farmed lands as good wildlife habitat. A walk around southern English farmland shows it to be an almost green desert for native wildlife. Perhaps appreciation of this situation is behind the RSPB's current editorial statement, which states '...nature needs a home. At all scales, from your back garden, local park or school grounds to our expansive and most iconic landscapes, nature thrives if it has a safe place to live' (Clarke, 2013). But will nature be wild in most of these settings?

Does this diminution of wildness matter and, if so, can anything be done about it? There are also cultural differences to consider: in many countries 'wild' means 'primitive' and hence an embarrassing liability and/or economically useless, and thus wild lands are prime targets for land-use conversion. Large areas of national parks in Ethiopia are being degazetted for commercial sugar cane, and for someone faced with the real risk of serious injury or death by a wild animal, or whose livelihood is threatened by damage from large carnivores or herbivores, the notion and desirability of 'wildness' may be different.

We started to think about the issue of wildness based on the case of the Arabian oryx Oryx leucoryx. Extinct in the wild in early 1970s, it has been reintroduced to five countries and eight sites, and was downlisted in 2011 to Vulnerable based on increased numbers (IUCN SSC Antelope Specialist Group, 2011). This reassessment provoked critical comment on the grounds that most of the animals are inside fenced enclosures and are too confined and too managed to count as wild, and should therefore not have been used for assessment. But two reserves with reintroduced oryx-Mahazat as-Sayd in Saudi Arabia and Umm al Zumoul in the UAE-cover 2,200 and $10,000 \mathrm{~km}^{2}$ respectively, areas that exceed those of some protected areas, and many ranches, game farms and conservancies in southern Africa. Considering animals in such southern African sites as non-wild would result in massive changes to the Red List and render some species ineligible for assessment. Confinement alone is thus not a useful determinant of wildness although clearly the space available per individual is key-determining the likelihood of self-sufficiency in its essential requirements.

We may be losing the wild as more sites, communities and populations of plants and animals and fungi receive direct or indirect interventions, intended or unintended. But does this matter? We live in an age of profound ecological change and surprise. Climate change is only starting to be treated as not just another threat but an overarching one that will interact with other threats. Will populations that have been relocated to where we think conditions will be more suited to them under changed climate regimes be considered wild?

Such assisted colonization for single species is only the beginning. So-called re-wilding is currently attracting great attention but any European efforts will inevitably be pale facsimiles, at best, of Pleistocene communities. The notion of novel climates requiring novel or designer ecosystems is gaining traction (Hobbs et al., 2013): can their populations be wild? Rather further from current conservation is synthetic biology: will new, man-made species or those restored from pre-extinction DNA ever be seen as wild?

We have a conundrum: very little wilderness is untouched in some way by human influence, and more plants and animals are affected than we probably wish to concede. Should we drop the notion of wild except for very rigorously defined circumstances, or continue believing quaintly that wild is a noble, albeit increasingly unrealistic ideal?

\section{References}

Clarke, M. (2013) Giving nature a home. Birds Magazine, Royal Society for the Protection of Birds, Autumn 2013.

Hobbs, R.J., Higgs, E.S. \& Hall, C.M. (eds) (2013) Novel Ecosystems: Intervening in the New Ecological World Order. John Wiley and Sons, London, UK.

IUCN SSC Antelope Specialist Group (2011) Oryx leucoryx. In IUCN Red List of Threatened Species v. 2013.1. Http://www. iucnredlist.org [accessed 30 July 2013].

IUCN Standards and Petitions Subcommittee (2013) Guidelines for Using the IUCN Red List Categories and Criteria. Version 10. Prepared by the Standards and Petitions Subcommittee. Http://www.iucnredlist.org/documents/RedListGuidelines.pdf [accesssed 3 September 2013].

Pearce, F. (2013) True nature: revising ideas on what is pristine and wild. Environment 360. Http://e360.yale.edu/feature/ true_nature_revising_ideas_on_what_is_pristine_and_wild/2649 [accesssed 3 September 2013].

PyLE, R.M. (2003) Nature matrix: reconnecting people and nature. Oryx, 37, 206-214.

Redford, K.H., Amato, G., Baillie, J., Beldomenico, P., Bennett, E.L., Clum, N. et al. (2011) What does it mean to successfully conserve a (vertebrate) species? BioScience, 61, 39-48. 